J. Lake Sci. (湖泊科学), 2018, 30(6): 1681-1692

DOI 10. 18307/2018. 0620

(c) 2018 by Journal of Lake Sciences

\title{
富营养化湖泊典型水华蓝藻的固有光学特性
}

\author{
张壹萱 ${ }^{1,2}$,张玉超 ${ }^{1,3 * *}$, 周 雯 $^{4}$, 张 民 ${ }^{1}$,马荣华 ${ }^{1,3}$ \\ ( 1 : 中国科学院南京地理与湖泊研究所,中国科学院流域地理学重点实验室,南京 210008) \\ (2: 中国科学院大学, 北京 100049) \\ (3:淮阴师范学院,江苏区域现代农业与环境保护协同创新中心,淮安 223001) \\ (4:中国科学院南海海洋研究所, 广州 510301)
}

\begin{abstract}
摘 要: 固有光学特性是水体光学特性的重要内容, 掌握富营养化湖泊水体内典型水华蓝藻的固有光学特性, 是开展不 同水华蓝澡遥感识别的理论基础. 利用 AC-S 吸收衰减仪、BB9 后向散射仪, 通过实验室纯藻培养, 研究微囊藻 ( Microcystis)、鱼腥藻 (Dolichospermum) 和束丝藻 (Aphanizomenon) 3 种典型水华蓝藻的固有光学特性, 并探讨色素浓度、色素占比以 及藻类等效粒径对不同水华蓝藻固有光学特性的影响. 结果表明, 3 种典型水华蓝藻的吸收光谱曲线均具有 $440 、 620$ 和 $675 \mathrm{~nm}$ 吸收峰, 微囊藻 620 和 $675 \mathrm{~nm}$ 的比吸收系数最大, 鱼膆藻 $440 \mathrm{~nm}$ 处的比吸收系数最大; 束丝藻单位色素浓度的散 射和后向散射能力最高, 鱼腥藻次之, 微囊藻最低; 固有光学特性影响因子分析表明, 色素浓度和藻蓝素占比是影响 3 种 水华蓝藻固有光学特性的主要因素. 3 种蓝藻的吸收系数、散射系数以及鱼腥藻、束丝藻的后向散射系数均随着色素浓度 (叶绿素 $\mathrm{a}$ 或藻蓝素) 的增加而增大; 当蓝藻中藻蓝素占比增加时, 3 种蓝藻的单位色素浓度的后向散射系数逐渐下降; 而 藻细胞粒径与固有光学特性之间并未表现出很好的相关性. 因此, 3 种水华蓝藻单位色素浓度的固有光学特性将为典型 水华蓝藻的遥感识别提供重要的理论基础和数据支持.
\end{abstract}

关键词: 富营养化湖泊;水华蓝藻;固有光学特性;吸收;散射;后向散射;微囊藻;鱼腥藻;束丝藻

\section{Inherent optical properties of typical cyanobacteria in eutrophic lakes}

\author{
ZHANG Yixuan ${ }^{1,2}$, ZHANG Yuchao ${ }^{1,3 * *}$, ZHOU Wen ${ }^{4}$, ZHANG Min $^{1} \&$ MA Ronghua ${ }^{1,3}$ \\ (1: Key Laboratory of Watershed Geographic Sciences, Nanjing Institute of Geography and Limnology, Chinese Academy of \\ Sciences, Nanjing 210008, P.R. China) \\ (2: University of Chinese Academy of Sciences, Beijing 100049, P.R.China) \\ ( 3: Jiangsu Collaborative Innovation Center of Regional Modern Agriculture \& Environmental Protection, Huaiyin Normal Uni- \\ versity, Huai'an 223001, P.R.China) \\ (4: South China Sea Institute of Oceanology, Chinese Academy of Sciences, Guangzhou 510301, P.R.China)
}

\begin{abstract}
Inherent optical properties are the important content of the optical properties of the water body. The inherent optical of cyanobacteria provides theoretical basis for remote sensing-based monitoring on cyanobacteria bloom. In this paper, inherent optical properties including absorbing, scattering and backscattering properties were measured for three typical cyanobacteria species in eutrophic lakes of China, cultured by AC-S and BB9 in the laboratory:Microcystis, Dolichospermum and Aphanizomenon. Pigmentspecific absorbing, scattering and backscattering coefficients were utilized to represent absorbing and scattering ability. The results showed that all of the three cyanobacteria had the similar absorbing spectrum with the absorbing peaks at 440,620 and $675 \mathrm{~nm}$. Microcystis showed the highest specific-absorbing coefficient at 620 and $676 \mathrm{~nm}$, while Dolichospermum had the specific-absorbing peak at $440 \mathrm{~nm}$. Aphanizomenon had the strongest scattering and backscattering ability, and Microcystis had the weakest scattering and backscattering ability. The main factors affecting absorbing and scattering properties were the pigment concentration (chlorophyll-a or phycocyanin) and the ratio of phycocyanin and pigment concentration (chlorophyll-a and phycocyanin). The absorbing
\end{abstract}

* 国家自然科学基金项目 (41671371, 41471287) 和国家科技支撑计划课题 “十二五” 项目 (2015BAD13B06) 联合资 助. 2018-01-13 收稿; 2018-04-13 收修改稿. 张壹萱(1994 ), 女, 硕士研究生; E-mail:125333243@ qq.com.

** 通信作者;E-mail:yczhang@ niglas.ac.cn. 
spectrum and scattering spectrum of these three cyanobacterial rose as the pigment concentration increased. But the specific-backscattering coefficient got down with the increasing ratio of phycocyanin and pigment concentration. It also showed that for these three cyanobacteria there were no obvious correlations between the cyanobacteria particle size and their inherent optical properties.

Keywords: Eutrophic lakes; cyanobacteria; inherent optical properties; absorbing; scattering; backscattering; Microcystis; Dolichospermum; Aphanizomenon

水体富营养化已经成为世界性环境问题, 蓝藻水华的频繁暴发则是水体富营养化带来的一个突出问 题 ${ }^{[1]}$. 大规模的蓝藻水华不仅会降低水资源利用效能,产生严重的生态破环及巨大的经济损失, 蓝藻毒素还 对公众健康有极大隐患 ${ }^{[2]}$. 研究表明, 引起蓝藻水华的种类主要有微囊藻 (Microcystis)、鱼腥藻 (Dolichospermum) 、鞘颤藻 (Lyngbya) 、束丝藻 (Aphanizomenon) 和颤藻 (Oscillatoria $)^{[1-2]}$. 不同湖泊蓝藻水华的优势种亦不 同, 甚至同一湖泊在不同时期或者不同区域亦存在不同的水华蓝藻优势种 ${ }^{[2]}$. 日本琵琶湖主要水华蓝藻为 微囊藻 ${ }^{[3-4]}$, 而霞浦湖, 在 $1970 \mathrm{~s}-1980 \mathrm{~s}$ 以微囊藻为优势藻种, 之后浮丝藻取代微囊藻成为优势藻种 ${ }^{[5-6]}$; 瑞 典 Finjasjön 湖则是硅藻、绿藻、蓝藻和甲藻共存形式取代了微囊藻 ${ }^{[7]}$; 新西兰内陆湖主要水华蓝藻为铜绿微 囊藻和鱼腥藻 ${ }^{[8-10]}$. 我国已经成为世界上蓝藻水华暴发最严重、分布最广的国家之一 ${ }^{[11]}$, 形成水华的蓝藻主 要有微囊藻、鱼腥藻、束丝藻和颤藻等 ${ }^{[12-13]}$, 其中太湖则以微囊藻为主 ${ }^{[1-15]}$, 巢湖以微囊藻和鱼腥藻为主, 部 分区域以束丝藻为主 ${ }^{[16]}$, 而滇池则以微囊藻和束丝藻为主 ${ }^{[17-18]}$. 不同蓝藻水华藻毒对人体危害不同, 铜绿 微囊藻产生的毒素可引发肝癌, 其中产生的毒素 MC-LR 危害最大 ${ }^{[19]}$, 鱼腥藻毒素会危害人体神经系统, 还 有一些蓝藻接触后可引起皮肤过敏甚至具有促癌性, 因此开展湖泊典型水华蓝藻种群识别, 对于治理湖泊 环境、保护人类健康有重要意义.

传统藻类识别方法大都是利用藻类的细胞形态特征以及蓝藻体内内含物 (DNA、色素) 的差异性进行区


学特征的高效液相色谱法 (HPLC) ${ }^{[23-24]}$ 、苂光光谱法 ${ }^{[25]}$ 和吸收光谱法 ${ }^{[26]}$. 以上传统识别方法均基于野外采 样和实验室内分析, 难以快速获取大范围水域上藻种的时空变化特征, 因此利用遥感技术开展对不同水华 蓝藻的识别具有十分重要实践意义和应用价值.

水体的遥感反射比是藻类遥感监测的基本参量, 同时遥感反射比又是水体吸收和后向散射系数的函 数 ${ }^{[27-28]}$, 因此充分认识和掌握水体中浮游植物的固有光学特性 (吸收、散射特性) 是开展藻类遥感识别的理 论基础. 现有研究主要针对海洋中的绿藻、褐藻、红藻以及赤潮藻等开展了吸收光谱以及苂光光谱方面的研 究 ${ }^{[29-33]}$; 针对内陆富营养化湖泊, 马万泉等 ${ }^{[4-39]}$ 基于室内控制试验及模拟试验, 开展了内陆湖泊蓝藻门(铜 绿微囊藻, Microcystis aeruginosa)、绿藻门 (小球藻, Chlorella vulgaris)、硅藻门(梅尼小环藻, Cyclotella meneghiniana) 以及隐藻门 (卵形隐藻, Cryptomonas ovata) 的固有光学特性研究, 并探索性地建立了各藻种占比 的遥感估算方法. 但是, 专门针对内陆富营养化湖泊典型水华蓝藻如微囊藻、鱼腥藻、束丝藻的固有光学特 性及其遥感识别方面还未见相关研究报道, 因此亟待在其固有光学特性 (吸收特性、散射特性、后向散射特 性) 及其影响因子等方面开展相关研究.

本研究以微囊藻、鱼腥藻、束丝藻 3 种典型水华蓝藻为研究对象, 通过室内光学控制实验, 开展 3 种典型 水华蓝藻固有光学特性异同点及其影响因子方面研究, 为实现不同水华蓝藻间的遥感识别提供重要的理论 依据和技术支撑.

\section{1 实验部分}

\section{1 材料}

选用铜绿微囊藻、水华鱼腥藻、水华束丝藻 3 种蓝藻为实验材料, 3 种藻种培养基均为 BG-11. 藻种保存 在光照培养箱中进行培养, 培养条件: 温度设置为 $25^{\circ} \mathrm{C}$, 光照强度设置为 $2000 \mathrm{~lx}$, 光周期为 12 小时光照/ 12 小时黑暗.

\section{2 参数测量}

实验基础测量参数包含吸收系数、衰减系数、后向散射系数、藻类粒径分布、叶绿素 a 浓度和藻蓝素浓 度, 其中吸收系数与衰减系数可推算出散射系数. 
吸收和衰减系数的测量: 藻类的吸收和衰减系数测量仪器使用的为 Wetlabs 公司的高光谱吸收/衰减仪 (AC-S) , 吸收系数和衰减系数由狭窄的孔径接收器与大面积探测器来接收, 在 $400 \sim 730 \mathrm{~nm}$ 光谱范围内由 80 个波段输出, 光谱分辨率为 $4 \mathrm{~nm}$, 测量精准度为 $\pm 0.01 \mathrm{~m}^{-1}$, 与 DH4 数据采集装置结合, 可用于剖面测量和 定点连续观测. 在吸收系数、衰减系数的测量实验之前, 需要对仪器进行空气和纯水校准, 对仪器的清洁度 和可用度进行检测, 并进行预热 $15 \mathrm{~min}$ 以上, 待仪器稳定后采集数据 ${ }^{[40]}$.

后向散射系数的测量: 使用 Wetlabs 公司生产的后向散射仪 (BB9) 测量后向散射系数, BB9 使用的是 $117^{\circ}$ 的质心角度, 在外推总的后向散射系数时可以将误差降到最小, 测量精度为 $0.005 \mathrm{~m}^{-1}$, BB9 共有 9 个光 谱通道, 分别是 $412 、 440 、 488 、 510 、 532 、 595 、 650 、 676$ 和 $715 \mathrm{~nm}$, 可测量 9 个波段的后向散射或 7 个波段的后 向散射和 2 个荧光参数 (叶绿素、CDOM). 本文中使用 BB9 测量 9 个波段的后向散射, 测量时与 AC-S 同时 下放水中, 通过时间计数的关系与 AC-S 的时间匹配 ${ }^{[41]}$.

藻类粒径分布的测量: 使用马尔文粒径分布仪测量藻类粒径分布, 此仪器能检测 $0.02 \sim 2000 \mu \mathrm{m}$ 范围内 液体、固体和乳化液的粒度分析, 扫描速度为 1000 次/s. 粒径测量时, 以纯水作为背景值, 测量样品 3 次, 取 平均值作为样品粒径分布 ${ }^{[42]}$.

叶绿素 $\mathrm{a}$ 浓度的测量: 采用分光光度法测量叶绿素 $\mathrm{a}$ 浓度, 叶绿素采用 $90 \%$ 丙酮并反复冻融萃取,将 $90 \%$ 丙酮作为参照液, 在 UV-2600 中测定 750、663、645 和 $630 \mathrm{~nm}$ 波长下的吸光度,计算叶绿素浓度 ${ }^{[43]}$.

藻蓝素浓度的测量: 藻蓝素测量采用磷酸冻融法, 样品采用 $0.05 \mathrm{~mol} / \mathrm{L}$ 的磷酸盐缓冲液 (PBS) 反复冻融 萃取, 将 $0.05 \mathrm{~mol} / \mathrm{L}$ PBS 作为参照液, 在 UV-2600 中测定 $750 、 652$ 和 $615 \mathrm{~nm}$ 波长下的吸光度, 计算藻蓝素 浓度 ${ }^{[44]}$.

\section{3 实验步骤}

向一个高 $76 \mathrm{~cm}$, 直径 $60 \mathrm{~cm}$, 底部覆盖遮光黑色尼龙布的有机玻璃桶中加人 $150 \mathrm{~L}$ 纯水, 置于暗室, 将 带有后向散射测量仪 BB9、吸收衰减仪 AC-S 测量仪器的支架放人有机玻璃桶中, 确保水体没过镜头和吸收 衰减管. 第 1 次加人 $2 \mathrm{~L}$ 纯藻液, 之后以 $500 \mathrm{ml}$ 为梯度加人藻的母液 5 次, 最终达到有机玻璃桶内有 $4.5 \mathrm{~L}$ 藻的母液, 共 6 组实验数据, 每次加人藻液均需要进行充分摚拌, 待水面平静后接通 $12 \mathrm{~V}$ 电源测量水体光 谱, 测量其吸收、衰减与后向散射系数, 连续观测至观测值稳定, 同时采 $1 \mathrm{~L}$ 水样进行室内分析 ( 叶绿素、藻蓝 素及藻粒径). 由于束丝藻培养速度较慢, 纯藻母液为 $3.5 \mathrm{~L}$, 共 4 组实验数据.

\section{4 数据处理}

1.4.1 吸收、衰减系数后数据处理 由 AC-S 直接获得的是水体吸收系数 $a(\lambda)$ 和衰减系数 $c(\lambda)$, 为了得到 更为精确的吸收系数和衰减系数数据, 需对温度和盐度进行校正 ${ }^{[39]}$, 校正公式为:

$$
\begin{aligned}
a_{\mathrm{mts}}(\lambda) & =a_{\mathrm{m}}(\lambda)-\left[\psi_{\mathrm{t}}^{*}\left(t-t_{\mathrm{r}}\right)+\psi_{\mathrm{s}}^{*}\left(S-S_{\mathrm{r}}\right)\right] \\
c_{\mathrm{mts}}(\lambda) & =c_{\mathrm{m}}(\lambda)-\left[\psi_{\mathrm{t}}^{*}\left(t-t_{\mathrm{r}}\right)+\psi_{\mathrm{s}}^{*}\left(S-S_{\mathrm{r}}\right)\right]
\end{aligned}
$$

式中, $a_{\mathrm{m}}(\lambda)$ 和 $c_{\mathrm{m}}(\lambda)$ 分别为仪器直接测量的吸收系数和衰减系数, 代表了水体总吸收值减去光学纯水的 吸收值; $\psi_{\mathrm{t}}^{*}$ 和 $\psi_{\mathrm{s}}^{*}$ 分别为温度和盐度校正系数; $t$ 和 $S$ 分别为实测温度和盐度值; $t_{\mathrm{r}}$ 和 $S_{\mathrm{r}}$ 分别是校正的参考 温度和盐度; $a_{\mathrm{mts}}(\lambda)$ 和 $c_{\mathrm{mts}}(\lambda)$ 分别为温度和盐度校正后吸收系数和衰减系数.

$\mathrm{AC}-\mathrm{S}$ 测量吸收值时, 吸收管内壁会将水体造成的散射光再次反射回去, 因此对 AC-S 测量吸收值还需 进行散射校正. 本文散射校正采取比例校正法 ${ }^{[45]}$, 假定有参考波长, 且在该参考波长处, 颗粒和溶解材料的 吸收系数忽略不计,公式为:

$$
a_{\mathrm{t}}(\lambda)-a_{\mathrm{w}}(\lambda)=a_{\mathrm{mts}}(\lambda)-\frac{a_{\mathrm{mts}}\left(\lambda_{\mathrm{ref}}\right)}{\left[c_{\mathrm{mts}}\left(\lambda_{\text {ref }}\right)-a_{\mathrm{mts}}\left(\lambda_{\text {ref }}\right)\right]}\left[c_{\mathrm{mts}}(\lambda)-a_{\mathrm{mts}}(\lambda)\right]
$$

式中, $a_{\mathrm{t}}(\lambda)$ 为总颗粒物的吸收系数, $a_{\mathrm{w}}(\lambda)$ 为纯水的吸收系数.

1.4.2 后向散射系数后数据处理 由于 EC0-BB9 利用的是微球散射体, 由散射引起的衰减部分, 使用 Scale factor (由 Wetlabs 公司提供) 校正成为水体总体散射函数 ${ }^{[46]}$ :

$$
\beta(\theta, \lambda)=S F(\lambda) \times\left(b_{\mathrm{b}}(\lambda)-D C(\lambda)\right)
$$

式中, $\beta(\theta, \lambda)$ 为吸收校正前的总体散射函数, 其中 $\theta$ 为角度 $\left(117^{\circ}\right), \lambda$ 为波长; $S F$ 为校准比例因子, 随着测 量不同的波长, $S F$ 的设定不同; $b_{\mathrm{b}}(\lambda)$ 为 $\mathrm{BB} 9$ 测量参数输出; $D C$ 为黑色胶带覆盖 BB9 浸人水中获得的信 
号, 本实验设为 50 .

下一步对总体散射函数进行吸收校正 ${ }^{[46]}$ :

$$
\beta(\lambda)=\beta(\theta, \lambda) \exp (0.0391 a(\lambda))
$$

式中, $\beta(\lambda)$ 为吸收校正后的总体散射函数; $\beta(\theta, \lambda)$ 是吸收校正前的总体散射函数; $a(\lambda)$ 是相应波段的吸 收系数 (由 AC-S 获得). 由校正后得到的总体散射函数, 减掉纯水的总体散射函数, 就可获得总悬浮颗粒物 的总体散射函数 $\beta_{\mathrm{b}}(\lambda)$; 根据式 $(5)^{[47]}$ 得到总悬浮颗粒物的后向散射系数 $b_{\mathrm{bp}}(\lambda)$.

$$
b_{\mathrm{bp}}(\lambda)=2 \pi \cdot X \cdot \beta_{\mathrm{b}}(\lambda)(X=1.1 \text {, 误差为 } 4 \%)
$$

\section{2 结果与讨论}

\section{1 吸收特性}


图 13 种蓝藻的吸收光谱曲线

Fig.1 Absorption spectra of three cyanobacterial species

3 种典型水华蓝藻吸收系数的波谱特征趋势相 近, 吸收值均随着藻浓度的增加而增大; 440 和 675 $\mathrm{nm}$ 附近有叶绿素 $\mathrm{a}$ 的吸收峰, $620 \mathrm{~nm}$ 附近有藻蓝 素的吸收峰; 但鱼腥藻在 $620 \mathrm{~nm}$ 的吸收峰没有其 他 2 种蓝藻明显, 3 种蓝藻在 $620 \mathrm{~nm}$ 与 $675 \mathrm{~nm}$ 吸 收系数之比平均值分别为 $1.047 、 0.871$ 和 1.046 (图 1).

为了更好地比较 3 种水华蓝藻的吸收特性, 本 研究采用比吸收系数分析比较 3 种水华蓝藻的吸 收能力, 即所测吸收系数与叶绿素 $\mathrm{a}$ 浓度的比值. 鱼腥藻比吸收系数在 $440 \mathrm{~nm}$ 吸收峰值最大 $(0.0359$ $\left.\mathrm{m}^{2} / \mathrm{mg}\right)$, 表明该波段鱼腥藻的吸收能力最强, 微囊 藻与束丝藻比吸收系数相近, 分别为 0.0320 和 $0.0303 \mathrm{~m}^{2} / \mathrm{mg} ; 620 \mathrm{~nm}$ 处微囊藻比吸收系数 $(0.0169$ $\left.\mathrm{m}^{2} / \mathrm{mg}\right)$ 最大, 束丝藻在该波段的比吸收系数 $\left(0.0129 \mathrm{~m}^{2} / \mathrm{mg}\right)$ 略小于鱼腥藻 $\left(0.0137 \mathrm{~m}^{2} / \mathrm{mg}\right)$, 微 囊藻的比吸收系数比鱼腥藻和束丝藻分别高出 $23 \%$ 和 $31 \% ; 675 \mathrm{~nm}$ 处, 微囊藻的比吸收系数最大 $\left(0.0162 \mathrm{~m}^{2} / \mathrm{mg}\right)$, 鱼腥藻与微囊藻的比吸收系数略 低, 鱼腥藻的比吸收系数为 $0.0156 \mathrm{~m}^{2} / \mathrm{mg}$, 束丝藻 的比吸收系数最低, 为 $0.0124 \mathrm{~m}^{2} / \mathrm{mg}$ (图 2). Bricaud 和王桂芬等 ${ }^{[48-49]}$ 发现马尾藻海、南海北部 等浮游植物 $440 \mathrm{~nm}$ 比吸收系数范围为 $0.029 \sim$ $0.137 \mathrm{~m}^{2} / \mathrm{mg}$; 周虹丽等 ${ }^{[50]}$ 认为渤海的小球藻、扁 藻、裸甲藻在 $440 \mathrm{~nm}$ 比吸收系数为 $0.016 \sim 0.0879$ $\mathrm{m}^{2} / \mathrm{mg}$, 在 $675 \mathrm{~nm}$ 比吸收系数为 $0.0112 \sim 0.0549$ $\mathrm{m}^{2} / \mathrm{mg}$; 淡水湖优势藻种研究表明, 微囊藻和栅列藻 $440 \mathrm{~nm}$ 比吸收系数分别为 $0.036 \pm 0.0013$ 和 $0.023 \pm$ $0.0008 \mathrm{~m}^{2} / \mathrm{mg}, 675 \mathrm{~nm}$ 比吸收系数分别为 $0.038 \pm 0.0015$ 和 $0.025 \pm 0.0009 \mathrm{~m}^{2} / \mathrm{mg}^{[51]}$. 本研究所测的内陆湖水 华蓝藻的吸收能力比海洋藻类弱, 与淡水湖优势藻种吸收系数相近.

\section{2 散射特性}

3 种蓝藻散射值均呈现随着藻浓度的增加而增大 (图 3), 且波峰波谷愈加明显, 微囊藻与束丝藻均呈现 随波长增加而下降的趋势, 鱼腥藻的散射波谱则相对缓和且平滑; 在 $440 \mathrm{~nm}$ 附近, 3 种蓝藻均出现因叶绿素 吸收所产生的散射波谷; 在 $550 \mathrm{~nm}$ 附近, 微囊藻和束丝藻散射值开始骤降, 鱼腥藻散射值呈现平稳下降; 在 




图 23 种蓝藻的比吸收光谱曲线

Fig.2 Specific absorption spectra of three cyanobacterial species

$675 \mathrm{~nm}$ 附近, 微囊藻和鱼腥藻由于叶绿素 a 及胡萝卜素吸收产生了一个散射波谷值 ${ }^{[52]}$, 束丝藻在此波段没 有波谷值,光谱曲线平滑.


图 33 种蓝藻的散射光谱曲线

Fig.3 Scattering spectra of three cyanobacterial species

束丝藻单位叶绿素 a 浓度的散射系数在 $400 \sim 700 \mathrm{~nm}$ 之间均最大 $\left(0.144 \sim 0.266 \mathrm{~m}^{2} / \mathrm{mg}\right)$, 鱼腥藻次之, 微囊藻最小, 表明束丝藻的散射能力最强; 在 $440 \mathrm{~nm}$ 特征波谷处, 束丝藻单位叶绿素 a 浓度的散射系数比微 囊藻和鱼腥藻分别高出 $146 \%$ 和 $127 \%$, 微囊藻和鱼腥藻单位叶绿素 a 浓度的散射系数接近, 分别为 $0.10 \sim$ 0.12 和 $0.08 \sim 0.13 \mathrm{~m}^{2} / \mathrm{mg}$; 在 $675 \mathrm{~nm}$ 处, 微囊藻、鱼腥藻和束丝藻单位叶绿素 a 浓度的散射系数分别为 $0.0751 、 0.112$ 和 $0.150 \mathrm{~m}^{2} / \mathrm{mg}$ (图 4). 吕恒等 ${ }^{[37]}$ 总结了太湖、巢湖、滇池蓝藻水中微囊藻、普通小球藻、梅尼 小环藻以及卵形隐藻单位叶绿素 a 浓度的散射系数变化范围为 $0.03 \sim 0.35 \mathrm{~m}^{2} / \mathrm{mg}$. 本研究所测 3 种水华蓝 藻单位叶绿素 a 浓度的散射系数亦在其范围内. 


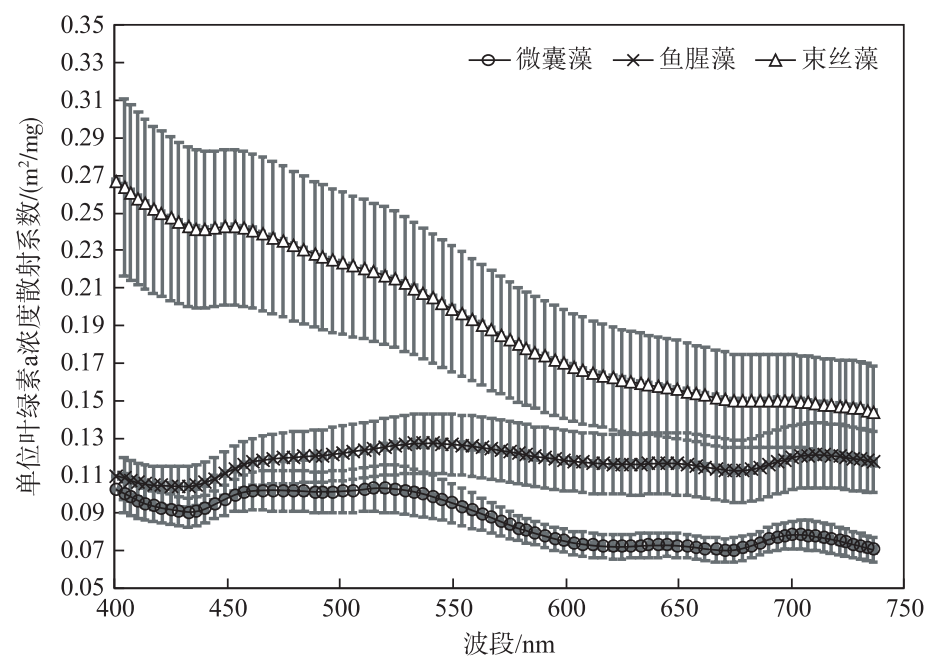

图 4 单位叶绿素 a 浓度下 3 种蓝藻的散射光谱曲线

Fig.4 Specific scattering spectra of three cyanobacterial species

\section{3 后向散射特性}

3 种水华蓝藻的 9 个波段后向散射系数可看出, 3 种蓝藻的后向散射曲线形状相近, 在 $488 \mathrm{~nm}$ 处有一个 明显波峰, 在 $510 \mathrm{~nm}$ 附近有一个明显波谷, 其他波段曲线平滑; $30 \mu \mathrm{g} / \mathrm{L}$ 以上的微囊藻后向散射系数接近, 曲线基本重合, 鱼腥藻与束丝藻后向散射系数均随浓度的增加而增大, 且变化明显; 束丝藻的后向散射系数 $\left(0.051 \sim 0.906 \mathrm{~m}^{-1}\right)$ 范围明显高于微囊藻和鱼腥藻的后向散射系数 $\left(0.0034 \sim 0.109 \mathrm{~m}^{-1}\right)$ (图 5).
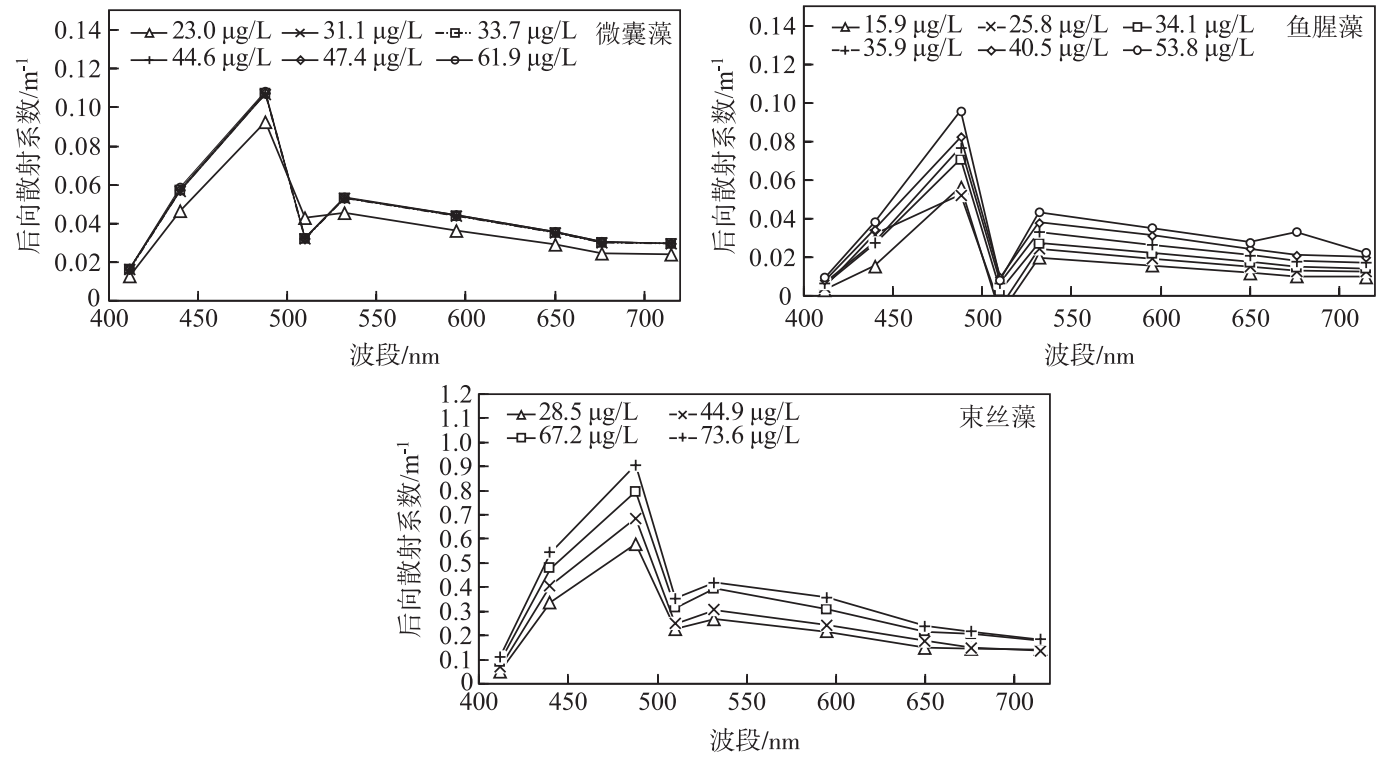

图 53 种蓝藻的后向散射光谱曲线

Fig.5 Backscattering spectra of three cyanobacterial species

由 3 种水华蓝藻单位叶绿素 $\mathrm{a}$ 浓度的平均后向散射系数可知, 3 种水华蓝藻单位叶绿素 $\mathrm{a}$ 浓度的平均 后向散射系数均在 $488 \mathrm{~nm}$ 处出现最大峰值, 在 $510 \mathrm{~nm}$ 处出现谷值; $488 \mathrm{~nm}$ 处束丝藻单位叶绿素 a 浓度后向 
散射值分别为微囊藻和鱼腥藻的 5.24 和 6.57 倍; 束丝藻单位叶绿素 a 浓度的后向散射值在各波段 均最大 $\left(0.0015 \sim 0.149 \mathrm{~m}^{2} / \mathrm{mg}\right)$, 微囊藻单位叶绿素 $\mathrm{a}$ 浓度的后向散射系数 $\left(0.0004 \sim 0.0028 \mathrm{~m}^{2} / \mathrm{mg}\right)$ 略 高于鱼腥藻 (0.0001 0.0023 $\mathrm{m}^{2} / \mathrm{mg}$ ) (图 6). 姜玲 玲等 ${ }^{[53]}$ 研究发现, 随着叶绿素浓度的增加海洋中肋 骨条藻的后向散射峰从 $442 \mathrm{~nm}$ 后移至 $488 \mathrm{~nm}$, 而 海洋的原甲藻和强壮前沟藻则始终位于 $488 \mathrm{~nm}$. 本 研究的 3 种水华蓝藻与海洋原甲藻、强壮前沟藻后 向散射峰位置一致;但与吕恒等 ${ }^{[38]}$ 研究中的铜绿微 囊藻后向散射峰谷位置有一定的差异, 但微囊藻单 位叶绿素浓度的平均后向散射系数数值与吕恒 等 ${ }^{[38]}$ 研究结果一致.

\section{4 固有光学特性影响因子}

2.4.1 固有光学特性与叶绿素 $\mathrm{a}$ 浓度的关系 叶绿 素 $\mathrm{a}$ 是浮游植物重要的指示性色素之一, 其浓度的

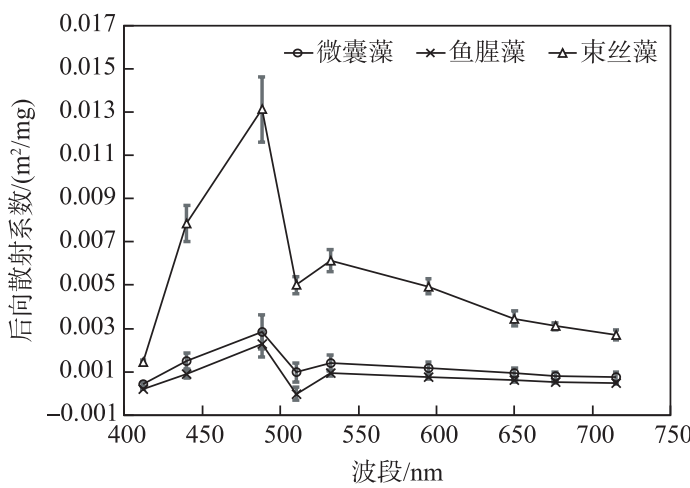

图 6 单位叶绿素 a 浓度下 3 种 蓝藻的后向散射系数曲线

Fig.6 Specific backscattering spectra of three cyanobacterial species under per unit chlorophyll-a concentration 大小反映了水体中浮游植物的数量, 是表征水体富 营养化程度的重要参数, 同时又是水体光学活性物质之一, 直接关系着水体的吸收和散射特性, 决定着光在 水体中的辐射传输过程 ${ }^{[43]}$. 本研究将 3 种水华蓝藻的叶绿素 a 浓度与其 $440 \mathrm{~nm}$ 的吸收、散射以及后向散射 系数做相关性分析 (图 7), 结果表明: 微囊藻、鱼腥藻以及束丝藻在 $440 \mathrm{~nm}$ 处吸收系数、散射系数均随着叶 绿素 a 浓度的增加而呈线性增加, 鱼腥藻和束丝藻的后向散射系数亦与叶绿素 a 浓度呈显著线性相关. 现有 研究表明, 叶绿素 $\mathrm{a}$ 浓度与 $440 \mathrm{~nm}$ 吸收系数间存在幂函数 ${ }^{[54]}$ 、多项式 ${ }^{[55]}$ 或者线性 ${ }^{[51]}$ 关系. 此外, 姜玲玲 等 ${ }^{[66-57]}$ 研究还发现强壮前沟藻后向散射与叶绿素 a 浓度呈很好的幕函数关系, 中肋骨条藻和海洋原甲藻后 向散射与叶绿素 $\mathrm{a}$ 浓度存在显著的线性关系. 本研究 3 种典型蓝藻叶绿素 $\mathrm{a}$ 浓度与吸收系数、散射系数以及 后向散射系数的关系均与已有研究结果一致.

相近叶绿素 a 浓度下,3 种水华蓝藻 $440 \mathrm{~nm}$ 处的吸收值非常接近,但在 $440 \mathrm{~nm}$ 的散射值和后向散射值 差异较大. 例如, 当微囊藻叶绿素 a 浓度为 $44.60 \mu \mathrm{g} / \mathrm{L}$ 时, 其散射和后向散射值分别为 3.853 和 $0.0575 \mathrm{~m}^{-1}$; 鱼腥藻叶绿素 a 浓度为 $40.49 \mu \mathrm{g} / \mathrm{L}$ 时, 其散射和后向散射值分别为 4.576 和 $0.0345 \mathrm{~m}^{-1}$; 束丝藻叶绿素 a 浓 度为 $44.88 \mu \mathrm{g} / \mathrm{L}$ 时, 其散射和后向散射系数则为 11.086 和 $0.406 \mathrm{~m}^{-1}$. 由此可见,在叶绿素 a 浓度相同情况 下, $440 \mathrm{~nm}$ 处束丝藻的散射系数和后向散射系数明显高于其他 2 种蓝藻, 微囊藻和鱼腥藻的散射系数和后 向散射系数数值相当.

2.4.2 固有光学特性与藻蓝素浓度的关系 藻蓝素是蓝藻的标志性色素, 尽管 3 种水华蓝藻均含有藻蓝素, 但是不同蓝藻的藻蓝素占比不同. 本研究发现, 3 种蓝藻的藻蓝素浓度均与 $620 \mathrm{~nm}$ 处的吸收系数、散射系数 呈线性关系, 且随着藻蓝素浓度增加而升高; 相同藻蓝素浓度的情况下, 微囊藻的吸收系数最大, 束丝藻的 散射系数最大; 单位藻蓝素浓度的后向散射系数与藻蓝素占比之间呈显著线性相关, 且 3 种水华蓝藻均表 现为当藻蓝素在色素中所占浓度比值越高, 其单位藻蓝素浓度后向散射系数越小. 与此相反, 当叶绿素 a 在 色素中比例上升时, 蓝藻单位藻蓝素浓度的后向散射系数呈明显增加的趋势. 在相同的单位藻蓝素浓度的 后向散射系数的情况下,束丝藻的藻蓝素占比最高, 微囊藻次之, 鱼腥藻最低 (图 8).

2.4.3 固有光学特性与粒径的关系 3 种典型水华蓝藻通过马尔文测量, 进行归一化呈现的粒径分布如图 9, 微囊藻平均等效球直径为 $3.3635 \pm 0.3990 \mu \mathrm{m}$, 鱼腥藻和束丝藻两种藻种平均等效球直径比微囊藻大, 分别 为 93.708 和 $68.108 \mu \mathrm{m}$; 微囊藻呈球形, 鱼腥藻和束丝藻则呈线状及丝状, 3 种水华蓝藻藻细胞粒径分布图 均呈现双峰分布, 说明 3 种蓝藻均存在抱团生长的现象.

浮游植物的固有光学特性不仅与其含有色素的组成和比例有关, 还与藻的粒径大小有关. 周雯等 ${ }^{[58-59]}$ 研究表明粒径不是影响吸收光谱的决定性因子, 仅存在间接相关, 粒径分布与衰减光谱斜率间关系存在非 



图 7 叶绿素 a 浓度与蓝藻固有光学特性的相关性

Fig.7 Relationships between chlorophyll-a concentrations and inherent optical properties of cyanobacteria

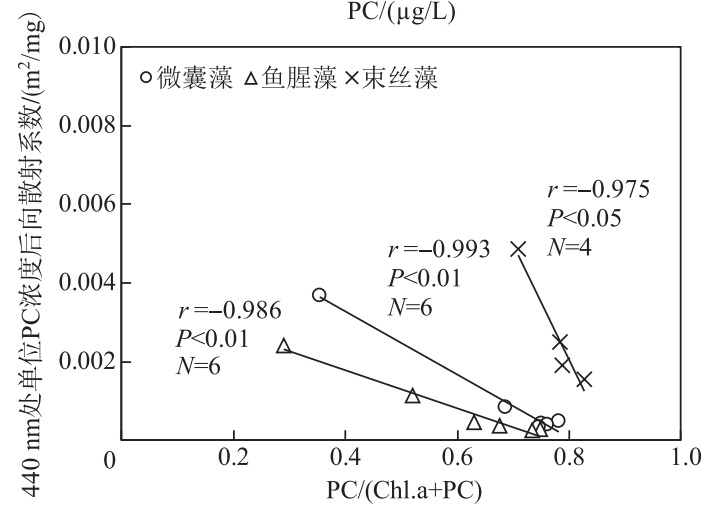

图 8 藻蓝素浓度与固有光学特性的相关性

Fig.8 Relationship between phycocyanobilin concentrations and inherent optical properties of cyanobacteria

单调变化关系; Bricaud 等 ${ }^{[60]}$ 认为藻类粒径结构变化的打包效应是比吸收系数的主要影响因素; Hirata 等 ${ }^{[61]}$ 发现藻类吸收光谱斜率随着粒径的增大而增大; 任智斌等 ${ }^{[62]}$ 基于 Mie 理论研究表明藻颗粒半径越大,散射 光强越集中; 姜玲玲 ${ }^{[56]}$ 发现不同粒径大小对水体后向散射的贡献规律很难确定,但后向散射截面与粒径呈 现良好的幂函数关系; 彭田 ${ }^{[63]}$ 则认为吸收效率、散射效率均受粒径变化的影响. 本实验结果表明:3 种水华 蓝藻的粒径与其固有光学特性间亦没有明确的相关性(图 10). 本研究与周雯等 ${ }^{[58]}$ 的研究结果一致,考虑到 本实验中后向散射实验数据偏少,该结论还有待进一步实验验证.

\section{3 结论}

微囊藻、鱼腥藻、束丝藻为我国内陆富营养化湖泊中主要水华蓝藻, 本研究基于室内光学控制实验, 开 




图 93 种蓝藻粒径分布

Fig.9 Particle size distribution of three cyanobacterial species



图 103 种蓝藻的等效球直径与固有光学特性的相关性 Fig.10 Relationship between equivalent ball diameter and inherent optical properties of three cyanobacterial species

展了 3 种水华蓝藻的固有光学特性研究, 结果表明, 3 种典型水华蓝藻的吸收光谱曲线均具有 $440 、 620$ 和 $675 \mathrm{~nm}$ 吸收峰, 微囊藻 620 和 $675 \mathrm{~nm}$ 的比吸收系数最大, 鱼腥藻 $440 \mathrm{~nm}$ 的比吸收系数最大; 束丝藻单位色 素浓度的散射和后向散射能力最高, 鱼腥藻次之, 微囊藻最低; 固有光学特性影响因子分析表明, 色素浓度 和藻蓝素占比是影响 3 种水华蓝藻固有光学特性的主要因素. 3 种蓝藻的吸收系数、散射系数以及鱼腥藻和 束丝藻的后向散射系数,均随着色素浓度 (叶绿素 a 或藻蓝素) 增加而增大; 当蓝藻中藻蓝素占比增加时, 3 种蓝藻的单位藻蓝素浓度的后向散射系数逐渐下降; 而藻细胞粒径与固有光学特性之间并未表现出很好的 相关性. 因此, 微囊藻在 620 和 $675 \mathrm{~nm}$ 处具有较高的吸收能力,鱼腥藻在 $440 \mathrm{~nm}$ 处有较高的吸收能力,束丝 藻较高的散射和后向散射能力都将为下一步 3 种水华蓝藻的遥感识别提供重要的理论依据.

\section{4 问题与展望}

本研究的室内光学控制实验中, 实验容器较大 $(200 \mathrm{~L})$, 需要大量的纯藻母液, 由于 3 种水华蓝藻的培 养周期较长 (2 6 周), 目前梯度实验样本数偏少, 因此需要持续开展纯藻种的室内光学控制实验, 累积样本 数据; 此外, 进行后向散射系数监测仪器 BB9 的监测位置需要进一步优化, 以进一步降低仪器架和实验容器 壁对其监测结果的影响. 基于室内纯藻种光学控制实验, 甄别表征不同水华蓝藻的吸收、散射及后向散射能 力的特征波段, 构建 3 种水华蓝藻的定量遥感监测方法, 实现富营养化湖泊典型水华蓝澡的空间分布的遥 感定量反演, 将成为今后研究的重点.

致谢: 感谢中国科学院南京地理与湖泊研究所和中国科学院水生生物研究所提供微囊藻、鱼腥藻和束丝澡 藻种母液, 感谢中国科学院南京地理与湖泊研究所“湖泊一流域科学数据共享平台”提供数据支持, 感谢张 海涛、丁红升、李晶、王点、曹志刚、梁其椿、沈明、郭西亚、房旭和熊俊峰等对藻种培养的指导以及实验采集 中的帮助.

\section{5 参考文献}

[ 1 ] Wang YC, Lu KH. Harm and control about cyanobacterial bloom. Chinese Journal of Fisheries, 2004, 17( 1) : 90-94. [王 扬才, 陆开宏. 蓝藻水华的危害及治理动态. 水产学杂志, 2004, 17(1) : 90-94.]

[ 2 ] Wu QL, Xie P, Yang LY et al. Studies on the mechanism of ecological disaster of harmful algal blooms in shallow lakes. Advanges Earth Science, 2008, 23(11): 1115-1123. [吴庆龙, 谢平, 杨柳燕等. 湖泊蓝藻水华生态灾害形成机理及 防治的基础研究. 地球科学进展, 2008, 23(11): 1115-1123.]

[ 3 ] Xie DL. Japan's Wuhu has improved water quality in 30 years. Environment and Life, 2013, (2): 34-37. [谢德良. 日本 琵琶湖 30 年治理水质好转. 环境与生活, 2013, (2) : 34-37.]

[ 4 ] Ozawa K, Fujioka H, Muranaka M et al. Spatial distribution and temporal variation of Microcystis species composition and microcystin concentration in Lake Biwa. Environmental Toxicology, 2005, 20(3) : 270-276. DOI:10.1002/tox.20117.

[ 5 ] Takamura N. Phytoplankton species shift accompanied by transition from nitrogen dependence to phosphorus dependence of 
primary production in lake Kasumigaura Japan. Arch Hydrobiol, 1992, 124: 129-148.

[ 6 ] Takamura N, Aizaki M. Change in primary production in Lake Kasumigaura (1986-1989) accompanied by transition of dominant species. Japanese Journal of Limnology, 1991, 52(3) : 173-187. DOI: 10.3739/rikusui.52.173.

[ 7 ] Annadotter H, Cronberg G, Aagren R et al. Multiple techniques for lake restoration. Hydrobiologia, 1999, 395/396 (1) : 77-85.

[ 8 ] Pridmore R, Kayetheredge M. Planktonic cyanobacteria in New Zealand inland waters: Distribution and population dynamics. New Zealand Journal of Marine \& Freshwater Research, 1987, 21(3) : 491-502.

[ 9 ] Parsons MJ. Biosystematics of the cryptogamic flora of New Zealand: Algae. New Zealand Journal of Botany, 1985,23 (4) : 663-675.

[10] Mccoll RHS. Chemistry and trophic status of seven New Zealand lakes. New Zealand Journal of Marine \& Freshwater Research, 1972, 6(4) : 399-447.

[11] Ma JA, Li HQ. Preliminary discussion on eutrophication status of lakes, reservoirs and rivers in China and overseas. Resources and Environment in the Yangtze Basin, 2002, 11(6): 575-578. [马经安, 李红清. 浅谈国内外江河湖库水体富 营养化状况. 长江流域资源与环境, 2002, 11(6) : 575-578.]

[12] Liu JT, Gao JF, Zhao JH et al. Method of cyanobacteria bloom hazard degree evaluation in Taihu Lake. China Environmental Science, 2010, 30(6): 829-832. [刘聚涛, 高俊峰, 赵家虎等. 太湖蓝藻水华灾害程度评价方法. 中国环境科 学, 2010, 30(6): 829-832.]

[13] Liu Y. Studies on the diversity, spatial-temporal distribution, and physiological characters of Anabaena flos-aquae in Lake Taihu[Dissertation]. Beijing: University of Chinese Academy of Sciences, 2013. [刘洋. 太湖水华鱼腥藻的多样性、时 空分布及生理特性研究. 北京: 中国科学院大学, 2013.]

[14] Chen Y, Qin B, Teubner K et al. Long-term dynamics of phytoplankton assemblages: Microcystis-domination in Lake Taihu, a large shallow lake in China. Journal of Plankton Research, 2003, 25(4) : 445-453. DOI: 10.1093/plankt/25.4.445.

[15] Deng J, Qin B, Paerl HW et al. Earlier and warmer springs increase cyanobacterial (Microcystis spp.) blooms in subtropical Lake Taihu, China. Freshwater Biology, 2014, 59(5) : 1076-1085. DOI: 10.111/fwb.12330S.

[16] Zhang M, Yu Y, Yang Z et al. The distribution of phytoplankton along trophic gradients and its mediation by available light in the pelagic zone of large eutrophic lakes. Canadian Journal of Fisheries \& Aquatic Sciences, 2012, 69(12) : 1935-1946. DOI: $10.1139 /$ f2012-113.

[17] Zhang M, Zhang YC, Yang Z et al. Spatial and seasonal shifts in bloom-forming cyanobacteria in Lake Chaohu: Patterns and driving factors. Phycological Research, 2016, 64(1): 44-55. DOI: 10.1111/pre.12112.

[18] Paerl HW, Otten TG. Harmful cyanobacterial blooms: Causes, consequences, and controls. Microbial Ecology, 2013,65 (4) : 995-1010. DOI: 10.1007/S00248-012-0159-Y.

[19] Li XY. Studies on the toxicology of microcystins [Dissertation]. Wuhan: Institute of Hydrobiology, Chinese Academy of Sciences, 2001. [李效宇. 微囊藻毒素的毒理学研究 [学位论文]. 武汉: 中国科学院水生生物研究所, 2001.]

[20] Lu L. Study on fluorescence spectra for identifying phytoplankton community[Dissertation]. Qingdao: Ocean University of China, 2007. [卢璐. 浮游植物群落组成苂光识别测定方法研究 [ 学位论文]. 青岛: 中国海洋大学, 2007.]

[21] Utermöhl H. Zur vervollkommung der quantitativen phytoplankton-methodik. Mitteilungen Internationale Verein Limnologie Stuttgard, 1958, 9: 263-272.

[22] Aldrich J, Cullis CA. RAPD analysis in flax: Optimization of yield and reproducibility using klen Taq, 1 DNA polymerase, chelex 100, and gel purification of genomic DNA. Plant Molecular Biology Reporter, 1993, 11(2) : 128-141.

[23] Abaychi J, Riley J. The determination of phytoplankton pigments by high-performance liquid chromatography. Analytica Chimica Acta, 1979, 107: 1-11.

[24] Gao HF, Jiao NZ. Research progress on marine phytoplankton biomass and community composition determined from algal pigment analyses. Marine Sciences, 1997, 21(3) : 51-54. [ 高洪峰, 焦念志. 通过藻类色素分析估测海洋浮游植物生 物量和群落组成的研究进展. 海洋科学, 1997, 21(3): 51-54.]

[25] Falkowski PG, Kolber Z. Variations in chlorophyll fluorescence yields in phytoplankton in the world oceans. Australian Journal of Plant Physiology, 1995, 22(2) : 341-355.

[26] Kromkamp JC, Forster RM. The use of variable fluorescence measurements in aquatic ecosystems: Differences between multiple and single turnover measuring protocols and suggested terminology. European Journal of Phycology Phycol, 2003, 38: 103-112. DOI: 10.1080/0967026031000094094. 
[27] Gordon HR, Mccluney WR. Estimation of the depth of sunlight penetration in the sea for remote sensing. Applied Optics, $1975, \mathbf{1 4}(2): 413$

[28] Yin L, Tang JW, Song QJ. A method of classification for algal species based on remote sensing reflectance spectra. Acta Oceanologica Sinica, 2011, 33(3) : 55-62. [殷蕾, 唐军武, 宋庆君. 基于遥感反射比光谱的一种藻类识别方法. 海 洋学报, 2011, 33(3) : 55-62.]

[29] Beutler M, Wiltshire KH, Meyer B et al. A fluorometric method for the differentiation of algal populations in vivo and in situ. Photosynthesis Research, 2002, 72 (1) : 39-53.

[30] Haxo FT, Blinks LR. Photosynthetic action spectra of marine algae. The Journal of General Physiology, 1950, 33 (4): $389-422$.

[31] Prangsma GJ, Roozekrans JN. Using NOAA AVHRR imagery in assessing water quality parameters. International Journal of Remote Sensing, 1989, 10(4/5) : 811-818.

[32] Zhou BC, Zheng SQ, Zeng CK. Comparison of absorption spectra of several Chlorophyta, Phaeophyta and Rhodophyta. Journal of Integrative Plant Biology, 1974, (2) : 146-155. [周百成, 郑舜琴, 曾呈奎. 几种绿藻、褐藻和红藻的吸收 光谱的比较研究. 植物生态学报: 英文版, 1974, (2) : 146-155.]

[33] Su RG, Liang SK, Hu XP et al. Discrimination of 6 toxic red tide algae occurred in east China sea by 3D fluorescence spectra. Marine Environmental Science, 2008, (3) : 265-268. [苏荣国, 梁生康, 胡序朋等. 我国东海常见 6 种有毒赤 潮藻的三维荧光光谱识别技术. 海洋环境科学, 2008, (3) : 265-268.]

[34] Ma WQ. Study on biological optical properties and remote sensing identification of Microcystis [ Dissertation]. Nanjing: Nanjing Normal University, 2012. [马万泉. 微囊藻生物光学特性与遥感识别研究. 南京: 南京师范大学, 2012.]

[35] Dai HL. The scattering characteristics and theoretical analog of the primary algae species in freshwater lakes. Nanjing: Nanjing Normal University, 2013. [ 戴红亮. 淡水湖泊主要藻种的散射特性和理论模拟研究 [ 学位论文]. 南京: 南京师 范大学, 2013.]

[36] Dai HL, Lv H, Li YM et al. A theoretical modeling of light absorption and scattering properties about Microcystis aeruginosa. Spectroscopy and Spectral Analysis, 2013, 33(6) : 1462-1467. [戴红亮, 吕恒, 李云梅等. 铜绿微囊藻吸收和散射 特性理论模拟. 光谱学与光谱分析, 2013, 33(6) : 1462-1467.]

[37] Lv H, Wang Y, Li XJ et al. Scattering and backscattering properties of main fresh water alga species. Bulletin of Botany, 2014, 49(5) : 578-586. DOI: 10.3724/SP.J.1259.2014.00578. [吕恒, 王瑜, 李晓俊等. 内陆湖泊主要藻种散射特 性. 植物学报, $2014,49(5): 578-586$.

[38 L L H, Dai HL, Li YM et al. Simulating the light absorption and scattering properties of Microcystis aeruginosa using a twolayered spherical geometry. Acta Optica Sinica, 2013, (12) : 319-329. [吕恒, 戴红亮, 李云梅等. 铜绿微囊藻吸收和 散射特性两层球形模型模拟. 光学学报, 2013, (12): 319-329.]

[39] Wang Y. Study on estimation of Microcystis aeruginosa proportion in Taihu Lake based on optical absorption spectra[Dissertation]. Nanjing: Nanjing Normal University, 2014. [王瑜. 基于吸收光谱的太湖铜绿微囊藻比例估算研究 [学位论 文]. 南京: 南京师范大学, 2014.]

[40] Fu DY, Ding YZ, Tao BY. Usingand data processing technique of underwater spectral absorption and attenuation meter. $O$ cean Technology, 2009, 28(3) : 101-105. [付东洋, 丁又专, 陶帮一. 水下光谱吸收衰减仪 ( ac-s) 的使用与数据处 理技术. 海洋技术学报, 2009, 28(3): 101-105.]

[41] Gu YZ, Liu YG. HydroScat-6 spectral backscattering sensor. Meteorlogical, Hydrological and Marine Instruments, 2008, (2) : 1-4. [顾艳镇, 刘玉光. 6 通道后向散射仪. 气象水文海洋仪器, 2008, (2): 1-4.]

[42] Wang Z, Zhang TY, Zhang ZH et al. Malvern Matersizer 2000 and its application. Guangdong Chemical Industry, 2015, 42(11) : 119-120. [万真, 张天一, 张志会等. 马尔文激光粒度分析仪 Mastersizer 2000 及其应用. 广东化工, 2015, 42(11): 119-120.]

[43] Lin SJ, He LJ, Huang PS et al. Comparison and improvement on the extraction method for chlorophyll a in phytoplankton. Ecoilogic Science, 2005, 24(1): 9-11. [林少君, 贺立静, 黄沛生等. 浮游植物中叶绿素 a 提取方法的比较与改进. 生态科学, 2005, 24(1): 9-11.]

[44] Pang XY, Duan HT, Zhang YC et al. Comparison of the extraction methods of phycocyanin pigments in eutrophic lake waters. J Lake Sci , 2014, 26(5) : 799-806. DOI: 10.18307/2014.0519. [ 庞晓宇, 段洪涛, 张玉超等. 富营养化湖泊水 体中藻蓝蛋白提取方法的对比. 湖泊科学, 2014, 26(5) : 799-806.]

[45] Chen LZ. Inherentoptical properties of oceanic and measurement methods in the field. Public Communication of Sicence \& Technology, 2013, (21) : 133-134. [陈立贞. 海洋光学固有光学参数及其现场测量方法. 科技传播, 2013, (21): 
133-134.]

[46] Lu WN. Post-processing and software implementation of water spectra data by remote sensing[Dissertation]. Nanjing: Nanjing Normal University, 2007. DOI: 10.7666/d.y1117727. [陆皖宁. 水体遥感实测光谱数据后处理与软件实现 [学位 论文]. 南京: 南京师范大学, 2007.]

[47] Boss E, Pegau WS. Relationship of light scattering at an angle in the backward direction to the backscattering coefficient. Applied Optics, 2001, 40(30): 5503-5507.

[48] Bricaud A, Stramski D. Spectral absorption coefficients of living phytoplankton and nonalgal biogenous matter: A comparison between the Peru upwelling areaand the Sargasso Sea. Limnology and Oceanography, 2003, 35(3) : 562-582.

[49] Wang GF, CaoWX, Xu DZ et al. Effects of size structure and pigment composition of algal population on phytoplankton absorption coefficients in the South China Sea. Acta Oceanologica Sinica, 2007, 29(1) : 38-48. [王桂芬, 曹文熙, 许大志 等. 南海北部藻类粒级结构及色素成分对浮游植物吸收系数的影响. 海洋学报, 2007, 29(1) : 38-48.]

[50] Zhou HL, Zhu JH, Han B et al. Comparison of spectral absorption characteristics of several typical algae. Ocean Technolo$g y, 2010,29(3): 78-81$. [周虹丽, 朱建华, 韩冰等. 几种典型藻种吸收光谱特性的比较. 海洋技术学报, 2010, $29(3): 78-81$.]

[51] Wang X, Zhang YL. Experimental study on absorption and scattering of Microcystis and Scendesmus. Transactions of Oceanology and Limnology, 2007, (z1) : 82-90. [王金金, 张运林. 微囊藻和栅列藻吸收与散射特性的实验研究. 海洋湖沼 通报, 2007, (z1): 82-90.]

[52] Liu K. Study onthe measurement of reflectance spectrum of inland water. Journal of Chongqing Normal University: Natural Science Edition, 2006, 23(4) : 71-75. [ 刘剋. 内陆水体反射波谱测量方法研究. 重庆师范大学学报: 自然科学版, $2006,23(4): 71-75$.

[53] Jiang LL, Wang L, Zhao DZ et al. Backscattering characteristics of amphidinium carterae hulburt. Spectroscopy and Spectral Analysis, 2013, 33(7) : 1892-1896. [姜玲玲, 王林, 赵冬至等. 强壮前沟藻的后向散射特性研究. 光谱学 与光谱分析, 2013, 33(7): 1892-1896.]

[54] Lutz VA, Sathyendranath S, Ejh H. Absorption coefficient of phytoplankton: regional variations in the North Atlantic. Marine Ecology Progress, 1996, 135(1/2/3) : 197-213.

[55] Cleveland JS. Regional models for phytoplankton absorption as a function of chlorophyll a concentration. Journal of Geophysical Research Oceans, 1995, 100(C7) : 13333-13344.

[56] Jiang LL. Thebackscattering properties of red tide alga and the remote sensing inversion model[Dissertation]. Dalian: Dalian Maritime University, 2014. [姜玲玲. 赤潮藻种后向散射特征机理及遥感反演方法研究 [ 学位论文]. 大连: 大连海事大学, 2014.]

[57] Jiang LL, Wang L, Zhao DZ et al. Spectral variability of particulate backscattering of nanoplankton and microplanktonFocusing on skeletonema costatum and prorocentrum micans. Marine Environmental Science, 2013, (6) : 884-888. [姜玲 玲, 王林, 赵冬至等. 微型和小型浮游藻类后向散射特性研究——中肋骨条藻和海洋原甲藻为例. 海洋环境科 学, 2013, (6): 884-888.]

[58] Zhou W, Sun ZH, Cao WX et al. Variations in the optical absorption and attenuation properties of cultured phytoplankton and their relationships with cell size. Spectroscopy and Spectral Analysis, 2012, 32(12): 3347-3352. [周雯, 孙兆华, 曹 文熙等. 浮游植物的吸收-衰减特性及其与粒径间的关系. 光谱学与光谱分析, 2012, 32(12): 3347-3352.]

[59] Boss E, Twardowski MS, Herring S. Shape of the particulate beam attenuation spectrum and its inversion to obtain the shape of the particulate size distribution. Applied Optics, 2001, 40(27) : 4885-4893.

[60] Bricaud A, Claustre H, Ras J et al. Natural variability of phytoplanktonic absorption in oceanic waters: Influence of the size structure of algal populations. Journal of Geophysical Research: Oceans, 2004, 109: C11010.

[61 ] Hirata T, Aiken J, Hardman-Mountford N et al. An absorption model to determine phytoplankton size classes from satellite ocean colour. Remote Sensing of Environment, 2008, 112(6) : 3153-3159.

[62] Ren ZB, Lu ZW, Liu YL et al. Study of mie normalized scattered intensity distributions. Journal of Optoelectronics Laser, 2003, 14(1) : 83-85. [任智斌, 卢振武, 刘玉玲等. Mie 理论归一化散射光强的研究. 光电子激光, 2003, 14(1): 83-85.

[63] Peng T. Distribution features and influencing factors in the absorption and scattering efficiencies of suspended particulate matters in the Yellow Sea and Bohai Sea[Dissertation]. Nanjing: Nanjing University of Information Science \& Technology, 2016. [彭田. 黄渤海悬浮颗粒物吸收散射效率分布特征及影响因素研究 [学位论文]. 南京: 南京信息工程大 学, 2016.] 